\title{
Vitamin D: no efficacy without deficiency. What's new?
}

\author{
A. Fassio, M. Rossini, D. Gatti \\ Rheumatology Unit, University of Verona, Italy
}

\section{VITAMIN D: \\ IS THE EMPEROR STANDING WITHOUT CLOTHES?}

Th the last two decades, scientific interest regarding vitamin $\mathrm{D}$ has increased greatly. This trend has led to the publication of a large number of papers, unfortunately often of low quality and based on misinterpreted assumptions (1-3). Currently, the role of vitamin D and its supplementation is still controversial, at best.

Many authors and opinion leaders seem to support the widespread use of vitamin D supplementation as a remedy for almost any health condition, advocating both its skeletal and extra-skeletal effects (4). At the other end of the spectrum, others limit its usefulness solely for the prevention/ treatment of few rare bone diseases (5).

Given the extent of the whole topic, and the difference in the strength of the evidence supporting the skeletal effect versus the extra-skeletal ones, this article's focus will be on the former. Indeed, data on the efficacy of vitamin D supplementation on extraskeletal effects are still uncertain $(3,6)$ and caution should be adopted before applying the same conclusions in these settings. In Italy, in 2017, 10.5 Defined Daily Doses of cholecalciferol were used every 1000 subjects, with a total cost near to 234 million euros and with a per-capita cost of 3.89 euros (7). Such extensive prescription is not necessarily appropriate. Arguably, a proportion of these subjects are young adults and/or people without any significant risk for vitamin $\mathrm{D}$ deficiency.

However, we should not forget that roughly $22 \%$ of the Italian population is over $65(8)$ and that the prevention strategies implemented in the last twenty years have shown to be effective in improving the overall vitamin D status in the elderly $(9,10)$, a population in whom its deficiency is notoriously more dangerous. This observation is striking especially in some Italian Regions such as in Veneto where, starting from the early 2000s, a community-based vitamin D supplementation campaign has been promoted by the two University Centres of Verona and Padua (11). This initiative, directed towards subjects aged over 70, was associated, a few years after its initiation, with a $10 \%$ reduction in hip fracture incidence (10). More recently, it has been even hypothesized to be one of the possible explanations for the declining trends in the incidence of hip fractures in Veneto in the population over 65 (years 2000 to 2011) (11). Indeed, hip fracture incidence in this Region appears to be in contrast with the global trend reported for the rest of Italy, where this strategy has not been adopted to date (11).

Recently, some large meta-analyses (5, 12), combining the results of several small trials with those of a few large trials to increase the statistical power of the analyses, concluded that vitamin D supplementation has no beneficial effects. This statement may induce a great deal of further confusion and misunderstanding, not only in the general population, but also in the health authorities and in fellow clinicians. In the last systematic review and meta-analysis by Bolland et al. (5), the authors concluded that vitamin D supplementation does not prevent fractures or falls, nor has clinically meaningful effects on bone mineral den-
Corresponding author: Angelo Fassio

Rheumatology Unit, Department of Medicine, University of Verona, P.co Borgo Roma

Piazzale A. Scuro, Verona, Italy E-mail: angelo.fassio@yahoo.it 
sity (BMD) and thus that there is little justification for using vitamin D supplements to maintain or improve musculoskeletal health. They also state that supplementation is necessary only for the rare conditions of rickets and osteomalacia, which may occur after a prolonged lack of exposure to sunshine leading to $25 \mathrm{OH}$-Vitamin D (25OHD) concentrations lower than 25 $\mathrm{nmol} / \mathrm{L}(10 \mathrm{ng} / \mathrm{mL})(5)$.

We agree with Bolland that there is no benefit in treating healthy subjects, especially when they are not even vitamin D deficient. However, we fear that these strong conclusions might confuse fellow practitioners and lead them to stop prescribing vitamin D supplementation indiscriminately in all patients, except for the ones with established rickets or osteomalacia. The concern is even higher if we consider elderly frail subjects and those affected by osteoporosis and therefore receiving treatment with bone acting agents.

It is known that, although bisphosphonates or denosumab are highly effective in preventing fractures (13), some patients will nonetheless fracture every year. Vitamin D deficiency has been shown to be one of the strongest predictors for fragility fracture in these patients and a decisive determinant of the skeletal response to the treatment itself $(14,15)$. An adequate vitamin $D$ intake should be considered imperative not only in the setting of rickets or osteomalacia but, at least, in all these patients.

\section{CRITICAL ISSUES OF THE META-ANALYSIS FROM BOLLAND ET AL.}

As with any systematic review, the choice of the included studies determines the quality and validity of the final results (and of the subsequent conclusions drawn from their interpretation). When analysing the meta-analysis from Bolland et al, one might wonder why two important placebocontrolled trials were excluded. In 1994 Chapuy et al. (16) showed in 3270 mobile elderly women that daily treatment with $1.2 \mathrm{~g}$ calcium and $800 \mathrm{IU}$ of cholecalciferol was able to decrease the probability of both hip fractures $(-29 \% ; \mathrm{p}<0.01)$ and all non-vertebral fractures $(-24 \%$; $p<0.01)$ after 36 months. In 1997 Dawson-Hughes et al. (17) studied the effects of three years of daily supplementation with $500 \mathrm{mg}$ calcium and $700 \mathrm{IU}$ vitamin D in 176 men and 213 women over 64 years who were living at home. This placebo-controlled study showed that this treatment reduced both the bone loss measured in the femoral neck, spine, and total body and the incidence of non-vertebral fractures. Of 37 subjects who presented non-vertebral fractures, 26 belonged to the placebo group and 11 to the calcium + vitamin D one $(\mathrm{p}<0.02)(17)$.

Furthermore, Bolland's meta-analysis included studies adopting different forms of vitamin $\mathrm{D}$, using frequent doses (or bolus) ranging from insufficient to extreme. The trial with greatest weight of fracture risk (18\%) (18) was hampered by low compliance $(54.5 \%)$, a recognized issue in this setting. $68 \%$ of the 81 trials included in the meta-analysis had a duration lower than or equal to 1 year. This is not an irrelevant detail, because this period of observation is too short to detect a distinct effect on long-term events (i.e. clinical fractures and BMD variations). For example, if we consider the first study which evaluated the effects of alendronate in postmenopausal women with low bone mineral density but without previous vertebral fractures (19), the lines of the graph depicting the cumulative incidence of clinical fractures in patients treated with alendronate (associated with calcium + vitamin D) vs placebo (associated with calcium + vitamin D) were still superimposable at the 12-months observation mark. In other words, at the twelfth month, the calcium + vitamin D group presented the same efficacy (or inefficacy) as a consolidated therapy such as alendronate. We also need to remember that, in subjects without previous vertebral fractures, the protective effect on the incidence of clinical fractures provided by alendronate $v s$ calcium + vitamin $\mathrm{D}$ alone was not even confirmed in the whole population ( $p=0.07)$, but only in the subgroup with osteoporosis diagnosed by DXA (19). 
Moreover, many of the studies considered by this meta-analysis included subjects at low risk for osteoporotic fracture. For instance, in the ViDA trial (20), only $2 \%$ of the vitamin D-supplemented group and $1 \%$ of the placebo group were affected by osteoporosis at baseline. It is also worth mentioning that roughly $46 \%$ of the enrolled subjects (in both groups) reported a history of fracture. However, given the low prevalence of osteoporosis and in the absence of further details, this data looks more confusing than informative, since most of those fracture events are arguably of traumatic nature and unrelated to bone health status. Further important considerations concern the age of the population involved in these studies: $41 \%$ of the patients were under 65 years of age and therefore quite unlikely to be at risk for falling. It is conceivable that all these critical points taken together might have contributed to the moderate heterogeneity observed.

Of the 81 studies considered, 42 evaluated fractures, 37 falls and 41 BMD. However, the authors themselves recognized that only $10(23.8 \%)$ studies were considered valid (low risk of bias) for fracture (5).

In our opinion, the most relevant limitation of this meta-analysis, and of the previous ones as well, lies in the fact that most of the studies enrolled individuals who were not vitamin D deficient ( $>20 \mathrm{ng} / \mathrm{mL}$ ) or who even attained sufficient levels $(30 \mathrm{ng} / \mathrm{mL})$ and were therefore unlikely to experience any benefit (21). Vitamin D deficient patients (i.e. $25 \mathrm{OHD}<25 \mathrm{nmol} / \mathrm{L}$ or $<10 \mathrm{ng} /$ $\mathrm{mL}$ ) only accounted for $831 / 39,485(2.1 \%)$ of the total patients in Bolland's metaanalysis (5)! This is a recurrent limitation affecting the studies published in the literature, and it originates from the assumption of vitamin D acting as a pharmacological agent, while it should be considered a micronutrient instead (21). Therefore, it is not surprising if its supplementation shows efficacy only in deficient subjects (21).

Flaws in the study population selection may also be found in the Vitamin D Assessment (ViDA) Study (20), a recent large trial included in Bolland's meta-analysis. The ViDA trial is a randomized, double- blind, placebo-controlled trial that involved 5110 healthy volunteers aged 50-84 years, randomly assigned to receive either an initial oral dose of 200,000 IU cholecalciferol followed by monthly 100,000 IU cholecalciferol or equivalent placebo dosing, with a mean treatment duration of 3.4 years. The mean blood 25OHD concentration at baseline was $63 \mathrm{nmol} / \mathrm{L}(25.2 \mathrm{ng} /$ $\mathrm{mL})$. Only about $2 \%$ of the subjects were 25OHD deficient, while over $30 \%$ had values even higher than ideal thresholds (i.e. $25 \mathrm{OHD}>75 \mathrm{nmol} / \mathrm{L}$ or $30 \mathrm{ng} / \mathrm{mL}$ ). As expected, the results failed to prove any benefit: the monthly high-dose boluses of cholecalciferol were not able to prevent falls or fractures in this healthy, ambulatory, adult population, without vitamin D deficiency. Nevertheless, it is interesting to note that a recent sub-analysis of the ViDA study, focusing on central blood pressure parameters, showed consistently favourable changes among the participants with vitamin $\mathrm{D}$ deficiency at baseline $(<50$ $\mathrm{nmol} / \mathrm{L}$ ), while nonsignificant changes in all hemodynamic parameters were found in the overall sample (22).

Interestingly, a few days after his metaanalysis, Bolland published two papers in which he stated that most of the available studies evaluating vitamin D supplementation can be considered research waste (1, 2 ), given the inclusion of a large proportion of vitamin D sufficient participants that is likely to have diluted the data on the benefits of vitamin D supplementation in the deficient ones. We completely agree with Bolland's statements and we are also concerned that meta-analyses stemming from these studies may be tainted to a similar extent.

In this regard, some authors suggest that future trials on vitamin D supplementation should recruit participants with low vitamin D levels (all with $25 \mathrm{OHD}<50 \mathrm{nmol} / \mathrm{L}$, and a good proportion with $<25 \mathrm{nmol} / \mathrm{L}$ ) and also suggest avoidance of supplementation with low-dose vitamin $\mathrm{D}$ in the placebo group. Unfortunately, we doubt that this proposal will represent a viable strategy in the future, especially given its clear ethical implications. 
A recently published randomized, placebocontrolled trial (3), with a two-by-two factorial design, of cholecalciferol (2000 IU per day) and omega- 3 fatty acids ( 1 g per day) for the prevention of cancer and cardiovascular disease (among men 50 years of age or older and women 55 years of age or older) failed to show that supplementation with vitamin $\mathrm{D}$ was able to lower the incidence of invasive cancer or cardiovascular events when compared to placebo. Among the 15,787 participants, the mean $( \pm$ SD) serum total 25OHD level at baseline was $30.8 \pm 10.0 \mathrm{ng} / \mathrm{mL}(12.7 \%$ had levels below $20 \mathrm{ng} / \mathrm{mL} ; 32.2 \%$ had levels from 20 to less than $30 \mathrm{ng} / \mathrm{mL} ; 55.1 \%$ had levels over or equal to $30 \mathrm{ng} / \mathrm{mL}$ ). Acknowledging the low proportion of participants with hypovitaminosis $\mathrm{D}$, the authors noted that a trial involving subjects with extremely low vitamin $\mathrm{D}$ levels (i.e., well below the $20 \mathrm{ng} / \mathrm{mL}$ ) would show stronger effects on risk. However, they also concluded that maintaining participants in a vitamin D-deficient state and circumventing real-world clinical care for 5 years would be neither ethical nor feasible.

At this point, one may wonder if a controlled trial vs. placebo is truly necessary to show the danger of a prolonged status of severe hypovitaminosis D.

In 2003 Smith and Pell (23) reminded us that the parachutes reduce the risk of injury after gravitational challenge but their effectiveness have not been proved with randomized controlled trials. In order to unravel this conundrum, very recently, Yeh et al. (24) brilliantly conducted the first randomized controlled trial on the protective effect of parachutes when jumping from aircrafts. Surprisingly, parachute use failed to show a reduction in death or major injury risk $(0 \%$ for the parachute group, $0 \%$ for the control group, $\mathrm{p}>0.9$ ). Logically, the authors concluded: should our results be reproduced in future studies, the end of routine parachute use during jumps from aircraft could save the global economy billions of dollars spent annually to prevent injuries related to gravitational challenge. The parachute paradox can literally be transposed to our vitamin D scrutiny, since in the present trial the rate of the primary outcome was substantially lower in this study than was anticipated at the time of its conception and design, which potentially underpowered our ability to detect clinically meaningful differences. Indeed, due to enrolment flaws, both groups jumped from a mean altitude of $0.6 \mathrm{~m}$ and with a mean aircraft velocity of $0 \mathrm{~km} / \mathrm{h}$. In the final paragraphs, the authors state: critics of the PARACHUTE trial are likely to make the argument that even the most efficacious of treatments can be shown to have no effect in a randomized trial if individuals who would derive the greatest benefit selectively decline participation.

As already stated, vitamin D is not a pharmacological agent and consequently its efficacy is not likely to be successfully investigated if addressed as one. Like parachutes, which cannot prevent any injury while walking on the street (or when jumping from a motionless aircraft), vitamin D supplementation is not likely to be appropriate or useful in subjects without deficiency. Therefore, a random and widespread administration approach makes little sense. Vitamin D deficiency is the actual problem, and, in conclusion, there is little doubt of its negative effects and the necessity for an adequate treatment when it is present.

Contributions: all the authors contributed equally.

Conflict of interests: AF reports personal fees from Abiogen and Novartis, outside the submitted work. MR reports personal fees from AbbVie, Abiogen, Amgen, BMS, Eli-Lilly, Novartis, Pfizer, Sanofi, Sandoz and UCB, outside the submitted work. DG reports personal fees from Abiogen, Amgen, Janssen-Cilag, Mundipharma and Pfizer, outside the submitted work.

\section{REFERENCES}

1. Bolland MJ, Grey A, Avenell A. Assessment of research waste part 2: wrong study populations- an exemplar of baseline vitamin D status of participants in trials of vitamin D 
supplementation. BMC Med Res Methodol. 2018; 18: 101.

2. Bolland MJ, Avenell A, Grey A. Assessment of research waste part 1: an exemplar from examining study design, surrogate and clinical endpoints in studies of calcium intake and vitamin D supplementation. BMC Med Res Methodol. 2018; 18: 103.

3. Manson JE, Cook NR, Lee I-M, et al. Vitamin D supplements and prevention of cancer and cardiovascular disease. N Engl J Med. 2019; 380: 33-44.

4. Holick MF. Resurrection of vitamin D deficiency and rickets. J Clin Invest. 2006; 116: 2062-72.

5. Bolland MJ, Grey A, Avenell A. Effects of vitamin D supplementation on musculoskeletal health: a systematic review, meta-analysis, and trial sequential analysis. Lancet Diabetes Endocrinol. 2018; 6: 847-58.

6. Scragg R. Emerging evidence of thresholds for beneficial effects from vitamin D supplementation. Nutrients. 2018; 10: 5.

7. Agenzia Italiana del Farmaco (AIFA). L'uso dei farmaci in Italia - Rapporto OsMed 2017 [cited 2018 Nov 16]. Available from: http:// www.aifa.gov.it/content/luso-dei-farmaci-italia-rapporto-osmed-2017

8. Demo-Geodemo. - Mappe, Popolazione, Statistiche Demografiche dell'ISTAT [cited 2018 Nov 9]. Available from: http://demo. istat.it/

9. Rossini M, Caimmi C, Giannini S, et al. The initiative on hip fractures of the Veneto $\mathrm{Re}$ gion. Clin Cases Miner Bone Metab Off J Ital Soc Osteoporos Miner Metab Skelet Dis. 2012; 9: 45-9.

10. Rossini M, Alberti V, Flor L, et al. Effect of oral vitamin D2 yearly bolus on hip fracture risk in elderly women: a community primary prevention study. Aging Clin Exp Res. 2004; 16: 432-6.

11. Giannini S, Sella S, Rossini M, et al. Declining trends in the incidence of hip fractures in people aged 65years or over in years 20002011. Eur J Intern Med. 2016; 35: 60-5.

12. Zhao J-G, Zeng X-T, Wang J, Liu L. Association between calcium or vitamin $\mathrm{D}$ supplementation and fracture incidence in communitydwelling older adults: a systematic review and meta-analysis. JAMA. 2017; 318: 2466-82.

13. Rossini M, Adami S, Bertoldo F, et al. Guidelines for the diagnosis, prevention and management of osteoporosis. Reumatismo. 2016; 68: 1-39.
14. Prieto-Alhambra D, Pagès-Castellà A, Wallace $\mathrm{G}$, et al. Predictors of fracture while on treatment with oral bisphosphonates: a populationbased cohort study. J Bone Miner Res Off J Am Soc Bone Miner Res. 2014; 29: 268-74.

15. Mosali P, Bernard L, Wajed J, et al. Vitamin $\mathrm{D}$ status and parathyroid hormone concentrations influence the skeletal response to zoledronate and denosumab. Calcif Tissue Int. 2014; 94: 553-9.

16. Chapuy MC, Arlot ME, Delmas PD, Meunier PJ. Effect of calcium and cholecalciferol treatment for three years on hip fractures in elderly women. BMJ. 1994; 308: 1081-2.

17. Dawson-Hughes B, Harris SS, Krall EA, Dallal GE. Effect of calcium and vitamin D supplementation on bone density in men and women 65 years of age or older. N Engl J Med. 1997; 337: 670-6.

18. Grant AM, Avenell A, Campbell MK, et al. Oral vitamin D3 and calcium for secondary prevention of low-trauma fractures in elderly people (Randomised Evaluation of Calcium Or vitamin D, RECORD): a randomised placebo-controlled trial. Lancet Lond Engl. 2005; 365: 1621-8.

19. Cummings SR, Black DM, Thompson DE, et al. Effect of alendronate on risk of fracture in women with low bone density but without vertebral fractures: results from the Fracture Intervention Trial. JAMA. 1998; 280: 2077-82.

20. Khaw K-T, Stewart AW, Waayer D, et al. Effect of monthly high-dose vitamin D supplementation on falls and non-vertebral fractures: secondary and post-hoc outcomes from the randomised, double-blind, placebo-controlled ViDA trial. Lancet Diabetes Endocrinol. 2017; 5: 438-47.

21. Bischoff-Ferrari HA, Willett WC, Orav EJ, et al. A pooled analysis of vitamin $\mathrm{D}$ dose requirements for fracture prevention. N Engl J Med. 2012; 367: 40-9.

22. Sluyter JD, Camargo CA, Stewart AW, et al. Effect of monthly, high-dose, long-term vitamin D supplementation on central blood pressure parameters: a randomized controlled trial substudy. J Am Heart Assoc. 2017; 6: 10.

23. Smith GCS, Pell JP. Parachute use to prevent death and major trauma related to gravitational challenge: systematic review of randomised controlled trials. BMJ. 2003; 327: 1459-61.

24. Yeh RW, Valsdottir LR, Yeh MW, et al. Parachute use to prevent death and major trauma when jumping from aircraft: randomized controlled trial. BMJ. 2018; 363: k5094. 